\title{
Studi Awal Penerapan Distributed Generation untuk Optimalisasi PLTS Atap On Grid pada Pelanggan PLN Sistem Jawa Bali untuk Memenuhi Target EBT Nasional
}

\author{
Jauhar Fahmi ${ }^{1}$, Jaka Windarta ${ }^{1}$, Asep Yoyo Wardaya ${ }^{2}$ \\ ${ }^{1}$ Magister Energi, Sekolah Pascasarjana, Universitas Diponegoro; \\ ${ }^{2}$ Departemen Fisika, Fakultas Sains dan Matematika, Universitas Diponegoro; \\ Email :jauharfahmi@students.undip.ac.id (J.H), jakawindarta@lecturer.undip.ac.id (J.W.), \\ asepyoyowardaya@lecturer.undip.ac.id (A.Y.W);
}

\begin{abstract}
Abstrak : Penyediaan energi baru dan terbarukan yang lebih ramah terhadap lingkungan akhir-akhir ini lebih mengemuka tidak hanya karena energi fosil yang semakin menipis tapi sebagai bentuk tanggung jawab terhadap energi berkelanjutan. Namun pada tataran pelaksanaan meski pemerintah melalui KEN dan RUEN telah memberikan pedoman sejauh ini belum berjalan baik. Lebih khusus terhadap pemanfaatan energi surya yang secara ironis yang berpotensi terbesar justru pemanfaatannya paling sedikit. Makalah ini memberikan studi awal pada ide skema pemanfaatan energi surya melalui Photovoltaic (PV) atap yang terkoneksi jaringan on-grid tanpa penyimpanan energi sebagai pembangkitan terdistribusi Distributed Generation dengan memanfaatkan jaringan lisrik yang telah terkoneksi luas. Metode ini memanfaatkan keunggulan jumlah pelanggan yang sangat besar dan dengan memanfaatkan sebarannya yang luas dengan program pembiayaan nasional yang berbeda dengan penggunaan PLTS terpusat berskala besar.
\end{abstract}

Kata Kunci : PLTS rooftop/atap, on grid, Distributed Generation, EBT

\section{Pendahuluan}

setiap aktifitas manusia tidak lepas dari pemanfatan energi dalam berbagai bentuk. Dan tugas besar pemerintah adalah menjaga penyaluran energi dapat berkesinambungan dengan perencanaan yang baik dan berkeadilan sehingga bisa dirasakan seluruh masyarakat Indonesia baik saat ini maupun untuk generasi masa mendatang

Penyediaan energi hingga akhir Desember 2019 menurut data statistik PLN total kapasitas terpasang pembangkit di Indonesia adalah $62,8 \mathrm{GW}$, dengan perincian untuk jenis pembangkit adalah PLTU 20,8 GW(47,3\%), PLTGU 10.1GW (24,4\%), PLTD 3,7 GW (8,4\%), PLTMG 1,3 GW (3,1\%), PLTA 3.6 GW (8,2\%), PLTG 3,2 GW (7,3\%), PLTP 0,58 GW (1,3\%), PLT Surya dan PLT Bayu 15,62 MW $(0,04 \%)$ (ESDM, 2019a). Pembangkit dengan bahan bakar fosil gabungan masih mendominasi dengan porsi kapasitas terpasang sebesar 90,5\%, dan sisanya sebesar 9,5\% berasal dari energi baru dan terbarukan (EBT).

Dari sisi konsumsi energi listrik sendiri masih terus meningkat seiring dengan target rasio elektrikasi sesuai roadmap listrik untuk keadilan energi hingga ideal mendekati 100 persen pada 
tahun 2024 (ESDM, 2018). untuk seluruh masyarakat (beberapa artikel menyatakan pada diharapkan tercapai pada tahun 2020) dan peningkatan konsumsi listrik per kapita yang digunakan sebagai indikator kesejahteraan masyarakat dari $905 \mathrm{kWh} /$ kapita menjadi $1501 \mathrm{kWh} / \mathrm{kapita}$ di tahun 2027 (ESDM, 2018) dan pada 2050 mencapai $4425 \mathrm{kWh} / \mathrm{kapita}$ (BPPT, 2019). Di samping semakin banyaknya produk yang beralih dengan memanfaatkan listrik seperti kendaraan listrik, kompor listrik, mikrowave, pemanas air pendingin udara dan sebagainya.

Di sisi lain, berdasarkan data kementrian ESDM, cadangan energi fosil yang kita miliki sebenarnya sangat terbatas, jika tidak di temukan cadangan baru, cadangan minyak bumi sebesar 3,15 milyar barel akan habis dalam waktu 11 tahun, Sedangkan untuk gas bumi dengan cadangan 96,06 TSCF maka diperkirakan akan habis dalam 34 tahun ke depan. Dan untuk batubara sendiri bila mengikuti amanat RUEN untuk pengendalian maksimal produksi 400 juta ton maka batu bara akan bisa bertahan hingga 97 tahun, namun bila mempertahankan tingkat produksi sekarang maka akan berkurang menjadi 71 tahun (DEN, 2020). Dari sinilah pentingnya memiliki bauran energi terutama dari tipe EBT yang berkembang pesat akhir-akhir ini seiring meningkatkan kesadaran masyarakat dunia pentingnya energi yang hijau dan berkelanjutan. Dan sebagai dampak dari tingginya permintaan yang menyebabkan kemajuan teknologi dan efisiensi EBT yang lebih tinggi dan semakin rendahnya biaya konstruksi pembangkit EBT berdampak pada penjualan per KWh yang semakin murah dan terjangkau

\section{Tabel 1.}

Potensi Energi Baru Terbarukan (DEN, 2019)

\begin{tabular}{|c|c|}
\hline Jenis Energi & Potensi \\
\hline Tenaga Air & $94,3 \mathrm{GW}$ \\
\hline Panas Bumi 28 & $28,5 \mathrm{GW}$ \\
\hline \multirow[t]{2}{*}{ Bioenergi } & PLT Bio: 32,6 GW \\
\hline & BBN : 200 Ribu Bph \\
\hline Surya & 207,8 GWp \\
\hline Angin & $60,6 \mathrm{GW}$ \\
\hline Energi Laut & $17,9 \mathrm{GW}$ \\
\hline
\end{tabular}

Salah satu EBT yang cukup menjanjikan adalah energi surya yang potensinya secara total sebagai yang terbesar dan menjanjikan, mencapai 207,8 GWp dibandingkan dengan tenaga air 94,3 GW dan Angin 60,6 GW (DEN, 2019). Namun sayangnya pemanfaatannya hingga saat ini masih sangat minim. Beberapa tahun lalu biaya per kWh PLTS masih cukup mahal sehingga belum di lirik oleh pemerintah karena dapat membebani keuangan negara dengan adanya subsidi, tercatat dalam RUEN 2017, untuk data biaya pokok penyediaan tenaga listrik tahun 2015 untuk PLTS sebesar 8786 rupiah/kWh, dibandingkan PLTA $388 \mathrm{rupiah} / \mathrm{kWh}$ dan PLTU $661 \mathrm{rupiah} / \mathrm{kWh}$ (Perpres, 2017). Hal inilah yang menyebabkan kapasitas terpasang hingga kini dari PLTS masih sangat rendah. 
Vol. 2, No. 1, pp $1-13$

doi: $10.14710 /$ jebt.2021.10038

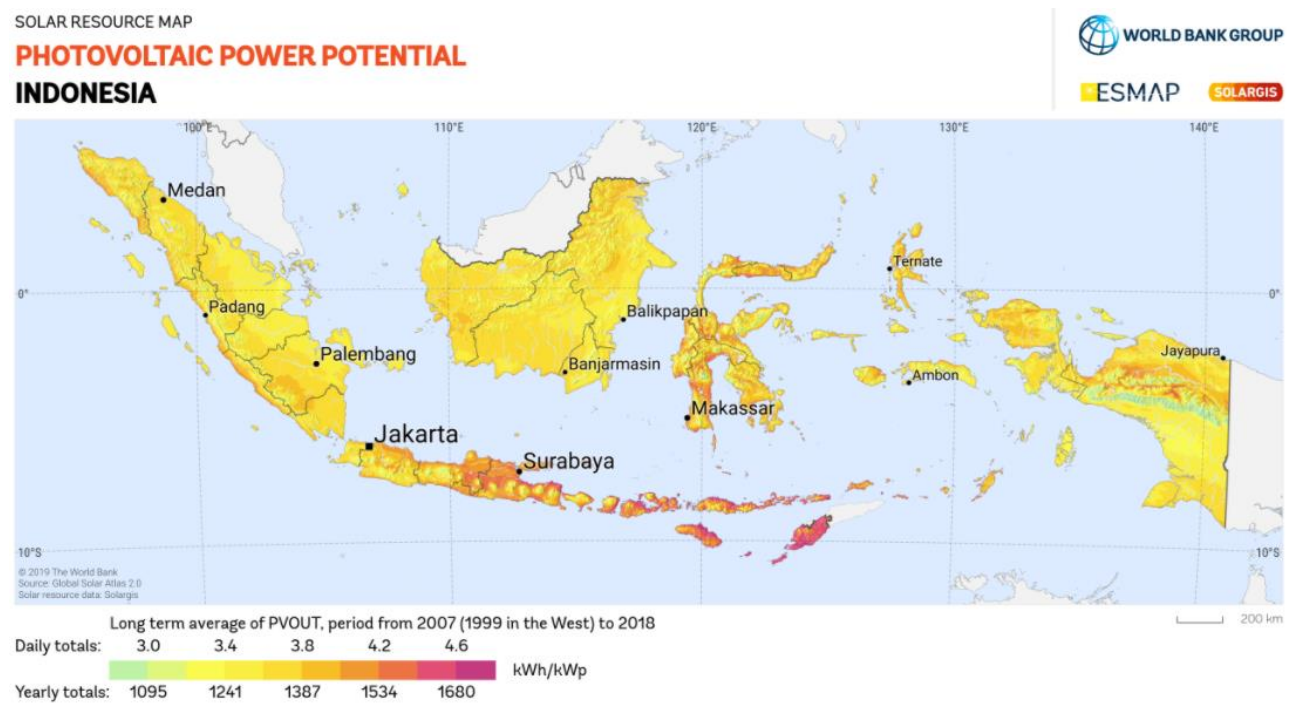

Gambar 1. Potensi Tenaga PV Energi Surya Indonesia (Solargis, 2017)

Menurut RUPTL PLN 2018-2027, target bauran energi untuk tahun rencana, diharapkan mencapai komposisi batubara 54,4\%, Gas 22,5\%, BBM 0,4\% atau total energi fosil 77,3\% dengan memberi peluang pada EBT untuk memiliki kenaikan lebih cepat hingga mencapai porsi lebih besar dari 22,7\% (ESDM, 2018). Banyak harapan di tanggung PLTS karena merupakan pembangkit yang lebih bersih dengan biaya operasinya yang rendah. Mengacu pada outlook BPPT, pangsa bahan bakar pembangkit dari surya pada tahun 2025 ditargetkan mencapai porsi 1 persen (BPPT, 2019), jika berdasar RUEN maka target pada tahun 2025 capaian PLTS diharapkan hingga 6500 MW (Perpres, 2017), atau jika berdasar RUPTL total rencana pengembangan PLTS diharapkan dapat mencapai target hingga 1047MW (ESDM, 2018).

Tabel 2.

Rencana Pengembangan Pembangkit EBT (MW) Berdasarkan RUPTL (ESDM, 2018)

\begin{tabular}{lccccccccccccc}
\hline \begin{tabular}{c} 
Pembangkit \\
\multicolumn{1}{c}{ EBT }
\end{tabular} & Satuan & 2018 & 2019 & 2020 & 2021 & 2022 & 2023 & 2024 & 2025 & 2026 & 2027 & Jumlah \\
\hline PLTP & MW & 210 & 150 & 221 & 235 & 405 & 445 & 355 & 2.537 & 20 & 5 & 4.583 \\
PLTA & MW & 66 & 287 & 193 & 755 & 315 & 196 & 635 & 4.461 & - & 564 & 7.472 \\
PLTMH & MW & 108 & 202 & 366 & 103 & 31 & - & - & - & - & - & 811 \\
PLT Surya & MWp & 5 & 22 & 214 & 281 & - & 200 & - & 325 & - & - & 1.047 \\
PLT Bayu & MW & 70 & 60 & 5 & 45 & 10 & 30 & 309 & - & - & 60 & 589 \\
PLT Bm/Sa & MW & 53 & 53 & 41 & 19 & 235 & - & - & - & - & 10 & 411 \\
PLT Kelautan & MW & - & - & - & - & - & - & - & - & - & - & - \\
PLT Bio-Fuel & Rb KL & 607 & 598 & 375 & 217 & 146 & 150 & 154 & 157 & 165 & 176 & 2.745 \\
\hline
\end{tabular}

*) Asumsi pemakaian biofuel hanya untuk PLTD 
Vol. 2, No. 1, pp $1-13$

doi: $10.14710 /$ jebt.2021.10038

\section{Amanat RUEN dan KEN}

Target dalam RUEN yang mencapai 6,5 GW memang cukup tinggi, meski data pada waktu itu, menunjukkan harga per kWh listrik PLTS masih sangat tinggi pada 8786 rupiah/kWh (Perpres, 2017). Dan sebagai perbandingan dari target RUEN di tahun 2019 PLTS diharapkan menghasilkan listrik sebesar 550MW, namun menurut buku statistik PLN kapasitas terpasang PLTS di tahun 2015 baru mencapai 14,65 MW (PT.PLN (Persero), 2019). Sehingga bila mendasarkan target yang lebih realistis dengan memakai RUPTL maka pada tahun 2025 diharapkan tercapai target PLTS sebesar 1 GW sesuai Tabel 2.

Namun membangun PLTS terpusat dengan kapasitas besar di suatu lokasi memiliki beberapa aspek yang perlu diperhitungkan, antara lain:

1) PLTS terpusat karena akan membutuhkan lokasi yang sangat luas yang saat ini sangat sulit dan mahal apalagi pada kawasan yang padat penduduk terutama untuk kawasan jaringan Jawa-Madura-Bali. Sebagai gambaran sederhana untuk sebuah PLTS terapung di Tiongkok menggunakan area seluan 1,4 km² atau sekitar 100 hektar untuk menghasilkan output sebesar 70 MW (Karpouzoglou dkk, 2020). Semakin rendah efisiensi PV dan teknologi (misalnya dengan tracker atau tidak) yang digunakan maka area yang dibutuhkan untuk menghasilkan keluaran listrik yang setara juga semakin besar.

2) Sebagaimana namanya, PLTS bergantung pada matahari atau saat siang hari saja (intermiten). Untuk mengatasinya solusi umum adalah penggunaan baterai atau konversi air dalam bentuk energi yang lain. Namun penyimpanan energi dari PV hingga saat ini masih belum feasibel baik secara ekonomi maupun teknis. Sehingga untuk memenuhi kebutuhan listrik saat energi surya tidak ada, masih membutuhkan pembangkit listrik konvensional (Liebensteiner \& Wrienz, 2020).

3) Efek cuaca, telah umum diketahui perolehan energi dari matahari akan mencapai puncaknya saat matahari bersinar paling terang dalam cuaca cerah. Saat tertutup awan atau cuaca hujan memang masih dapat menangkap energi namun efisiensinya jatuh cukup rendah. Pengaruh cuaca lokal inilah yang tidak disukai karena dapat mempengaruhi keluaran daya pembangkit dengan cepat. Semakin besar skala PLTS semakin besar pula fluktuasi profil listrik yang dihasilkannya dan semakin berpengaruh pada jaringan .

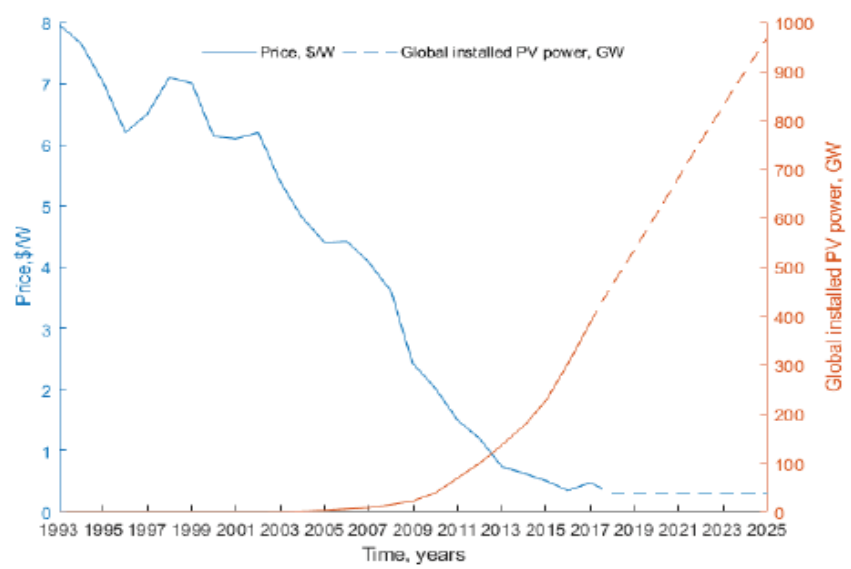

Gambar 2. Biaya perWatt dari panel PV dalam Kaitannya dengan Akumulasi Kapasitas Terpasang dengan Data di Seluruh Dunia (Allik \& Annuk, 2018) 
4) Pembiayaan yang cukup tinggi. Biaya awal pembangungan PLTS termasuk cukup tinggi, namun seiring dengan pengembangan teknologinya secara terus menerus, maka akan semakin terjangkau. Tercatat di seluruh dunia dalam sepuluh tahun terakhir terjadi peningkatan kapasitas terpasang PV sebesar 48 kali, dari 8 GW di 2007 menjadi 387 GW di tahun 2017. Sementara harga dari PV sendiri pada periode yang sama turun menjadi $12 \mathrm{kali}$ lebih rendah, membuat biaya pemasangan menjadi lebih murah (Allik \& Annuk, 2018). Gambar 2 menunjukkan tren penurunan harga solar panel seiring dengan kenaikan kapasitas instalasi PV dari tahun 1993 sampai 2017

Membangun PLTS dengan kapasitas besar memang akan memudahkan pencapaian target bila kendala di atas dapat tanggulangi, namun dalam RUEN sendiri sebenarnya telah memberi petunjuk bahwa untuk mencapai sasaran pengembangan PLTS di atas ada tiga hal yang bisa dilakukan, antara lain:

1) Memberlakukan kewajiban pemanfaatan sel surya minimum sebesar $30 \%$ dari luas atap untuk seluruh bangunan pemerintah.

2) Memberlakukan kewajiban pemanfaatan sel surya minimum sebesar $25 \%$ dari luas atap (rooftop) bangunan mewah, perumahan, kompleks melalui Izin Mendirikan Bangunan.

3) Memfasilitasi pendirian hulu hilir PLTS (Perpres, 2017)

Ketiga hal tersebut kelihatannya belum nampak sebagai suatu program besar yang harus serius dilakukan oleh pemerintah. Untuk itulah pada tulisan ini, berkonsentrasi pada tema optimalisasi ketiga amanat RUEN di atas agar tercapai target bauran energi baru terbarukan pada jenis PLTS berbasis PV. Studi optimalisasi PLTS Rooftop (atap) ini sebagai studi ide yang ditargetkan pada pelanggan PLN terkoneksi jaringan, sebagai contoh yaitu pelanggan interkoneksi Jaringan Jawa Bali, baik penerima subsidi maupun non subsidi dengan skema progam nasional PLTS on-grid tanpa penyimpanan energi.

Pemilihan skema on-grid tanpa penyimpanan adalah sebagai tahap awal program, dengan target untuk mengkompensasi kenaikan permintaan listrik pada jam kerja siang hari, sedangkan pemilihan optimalisasi PLTS atap pada poin 1 dan 2 di atas adalah untuk menanggulangi kekurangan PLTS terpusat yang sangat terpengaruh cuaca lokal/setempat. Dengan sebaran luas PLTS atap yang lebih merata pada seluruh wilayah, misalnya seluruh Jawa -Bali, pengaruh cuaca lokal yang menimpa suatu wilayah tapi tetap normal di wilayah lain, dapat meminimalisir dampak cuaca sehingga naik turun suplai listrik yang cepat (ramp up/ramp down) yang bisa mempengaruhi suplai jaringan dapat pula diminimalisir.

\section{PV atap On-grid sebagai Distributed Generation}

Sebuah eksperimen penelitian (oleh Windarta dkk., 2020) yang dilakukan di Semarang, Jawa Tengah Indonesia membandingkan penggunaan empat kombinasi PV dan inverter dengan desain ongrid tanpa penyimpanan energi pada skala rumah tangga dengan desain panel $3 \times 405=1.215 \mathrm{Wp}$ dengan 1000 watt inverter, yang menghasilkan listrik bervariasi antara $1.877-1.898 \mathrm{kWh}$, keempatnya memberikan payback period dalam jangka waktu hampir sama sekitar 10 tahun dengan pendanaan sendiri bukan pinjaman sebesar $25 \sim 26$ juta per instalasi.

Dengan duplikasi desain instalasi PV di atas maka beberapa perhitungan dapat diperkirakan. Dengan mengambil data dari BPS terkait jumlah pelanggan pada jaringan Jawa-Bali dan pada tiap sektor (BPS, 2018) diberlakukan pola partisipasi pelanggan sejumlah 2,45\% untuk memenuhi roadmap 
RUPTL, atau $10 \%$ atau $15 \%$ Untuk memenuhi target RUEN sehingga bisa didapat akumulasi total kapasitas terpasang PLTS atap. Pada tabel 3 di bawah dengan data pelanggan rumah tangga, industri, komersial, sosial dan gedung pemerintah yang diperoleh dari data BPS. Peserta target program adalah rumah tangga, sosial dan gedung pemerintah untuk memperoleh data kapasitas terpasang PLTS atap on-grid pada jaringan Jawa-Bali sebagai berikut

Tabel 3.

Data pelanggan PLN Tahun 2017 Berdasarkan Sektor pada Tiap Provinsi yang Tergabung dalam Jaringan Jawa-Bali Menurut Data BPS (BPS, 2018).

\begin{tabular}{ccccccc}
\hline Provinsi & Rumah Tangga & Industri & Komersial & Sosial & Gedung & Total \\
\hline DKI Jakarta & 3.856 .239 & 6.266 & 288.259 & 40.295 & 5.569 & 4.196 .628 \\
Jawa Barat & 12.389 .449 & 16.953 & 506.183 & 265.362 & 15.134 & 13.193 .081 \\
Jawa Tengah & 9.948 .614 & 9.294 & 443.812 & 274.955 & 22.603 & 10.699 .278 \\
D.I. Yogyakarta & 1.038 .569 & 675 & 59.581 & 28.623 & 3.069 & 1.130 .517 \\
Jawa Timur & 9.994 .368 & 23.726 & 66.209 & 287.422 & 18.783 & 10.390 .508 \\
Banten & 2.714 .121 & 6.624 & 152.190 & 52.740 & 3.586 & 2.929 .261 \\
Bali & 1.081 .694 & 1.112 & 202.578 & 34.238 & 3.968 & 1.323 .590 \\
\hline Total Sektor & 41.023 .054 & 64.650 & 1.718 .812 & 983.635 & 72.712 & 43.862 .863 \\
\hline
\end{tabular}

Tabel 4 memberikan Total kapasitas terpasang untuk partisipasi pelanggan 2,45\% atau sejumlah 1 juta pelanggan jaringan Jawa -Bali saja maka akan di dapat kapasitas terpasang PLTS atap sebesar 1022 MW cukup untuk memenuhi target RUPTL, dengan biaya program sebesar Rp 26 trilyun atau Rp. 5,2 trilyun per tahun, berdasarkan biaya sebesar 26 juta per instalasi sebagai acuan berdasar eksperimen (Windarta dkk, 2020). Sedangkan untuk memenuhi target RUEN diperlukan partisipasi 6,15 juta peserta dengan biaya program Rp 108,5 trilyun atau Rp 21,7 trilyun per tahun untuk jangka program 5 tahun. Penetapan 10\% ini sekedar memberi gambaran potensi PLTS atap. Penetapan peserta program awal yang rendah ini sebagai antisipasi berbagai kendala misalnya bisa terjadi kesulitan pemasangan PLTS pada atap rumah yang telah ada yang di sebabkan konstruksi atap ataupun arah atap yang mungkin tidak memberi keuntungan maksimal dari pemasangan PLTS, sehingga tidak semua atap memungkinkan untuk memperoleh instalasi PLTS atap.

Jumlah peserta yang mengikuti program ini tidak lagi dihitung sebagai jatah persentase di tiap provinsi, namun sebagai target dalam sebaran wilayah operasi Jawa-Bali, karena tujuan program ini adalah meningkatkan sebaran instalasi PV se merata mungkin untuk mengurangi dampak cuaca lokal, semisal DKI jakarta yang memiliki jumlah pelanggan banyak namun dengan area sempit maka persentase penerima program dibanding total pelanggan akan lebih rendah.

Pembiayaan ini dikalkulasi secara linier dengan tidak memperhitungkan biaya/bunga pinjaman, dan yang perlu di catat di sini pembiayaan ini sebagian akan langsung berangsur-angsur sejak bulan pertama terbayar oleh konsumen yang telah menerima instalasi seiring dengan perjalanan operasional program, sehingga biaya program bisa lebih rendah. Harga PV sendiri masih mungkin lebih rendah, mengingat pada eksperimen di atas adalah berdasarkan harga Panel PV dan inverter impor yang masih berdasar pada harga pasar. Dan dengan menjalankan amanat RUEN poin ke tiga tentang kemandirian produksi hulu dan hilir komponen PV (Perpres, 2017) maka biaya produksi akan bisa didapatkan lebih rendah lagi, apalagi mengingat potensi pengguna program yang cukup banyak dengan program multiyears. 
Vol. 2, No. 1, pp $1-13$

doi: $10.14710 /$ jebt.2021.10038

Tabel 4.

Perolehan Akumulasi Keluaran Daya Listrik dari Pelanggan Pada Tahun 2017

\begin{tabular}{|c|c|c|c|c|c|c|}
\hline \multirow[b]{2}{*}{ Parameter } & \multirow[b]{2}{*}{$\begin{array}{l}\text { Persen- } \\
\text { tase }\end{array}$} & \multirow[b]{2}{*}{ Satuan } & \multicolumn{3}{|c|}{ Sektor } & \multirow[b]{2}{*}{ Total } \\
\hline & & & RT & Sosial & $\begin{array}{c}\text { Gedung } \\
\text { Pemerintah }\end{array}$ & \\
\hline Total Pelanggan & & & 41.023 .054 & 983.635 & 72.712 & \\
\hline Target output Wp & & & 1.000 & 500 & 3.000 & \\
\hline \multirow{4}{*}{$\begin{array}{l}\text { Target Peserta } \\
(2021 \sim 2025)\end{array}$} & $2,45 \%$ & KWp & 1.005 .065 & 12.050 & 5.344 & 1.022 .459 \\
\hline & $10 \%$ & KWp & 4.102 .305 & 49.182 & 21.814 & 4.173 .301 \\
\hline & $15 \%$ & KWp & 6.153 .458 & 73.773 & 32.720 & 6.259 .951 \\
\hline & $50 \%$ & $\mathrm{KWp}$ & 20.511 .527 & 245.909 & 109.068 & 20.866 .504 \\
\hline \multirow{4}{*}{ Biaya Program (2021 2025) } & $2,45 \%$ & juta Rp & 26.131 .685 & 313.288 & 138.953 & 26.583 .926 \\
\hline & $10 \%$ & juta Rp & 106.659 .940 & 1.278 .726 & 567.154 & 108.505 .820 \\
\hline & $15 \%$ & juta Rp & 159.989 .911 & 1.918 .088 & 850.730 & 162.758 .729 \\
\hline & $50 \%$ & juta Rp & 533.299 .702 & 6.393 .628 & 2.835 .768 & 542.529 .098 \\
\hline Angsuran bulanan & 10 thn & $\mathrm{Rp}$ & 216.667 & 108.333 & 650.000 & \\
\hline
\end{tabular}

Pola pembangkit mikro pada PLTS atap on-grid yang terkoneksi dengan jaringan ini dengan jumlah banyak dengan kapasitas kecil pada umumnya kurang dari beberapa MW di beberapa literatur menyebut sebagai pembangkitan terdistribusi, Distributed Generation (Bhadoria dkk., 2013). Pembangkit pada program ini cenderung tidak melalui dispatcher dan berada pada level distribusi. Penelitian terhadap dampak DG masih termasuk sedikit (Fidalgo et al., 2009). DG ini tentu memiliki potensi baik negatif maupun positif, secara umum dampak positif dari DG terhadap sistem suport jaringan (Bhadoria dkk., 2013), antara lain:

1) Rendahnya rugi-rugi listrik (Manjunatha Sharma \& Vittal, 2010)

2) Reliabilitas dari pembangkit besar akan menjadi lebih baik (Bhadoria dkk., 2013)

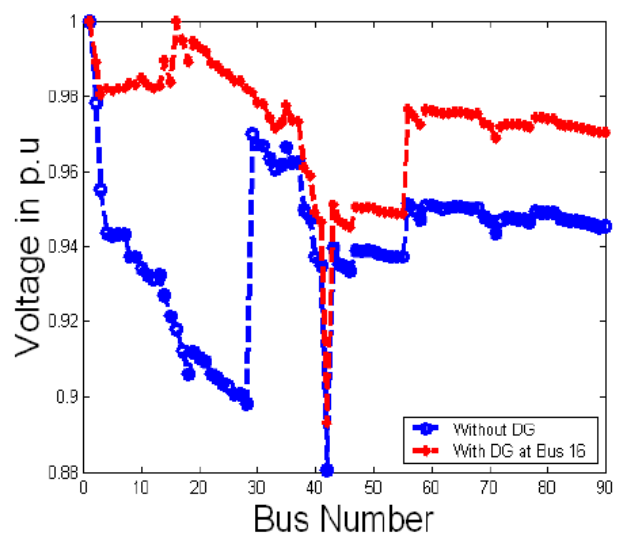

Gambar 3. Perbaikan tegangan pada jaringan dengan DG atau tanpa DG

3) DG dapat membantu menjaga tegangan jaringan sehingga lebih jauh dapat meningkatkan kualitas listrik pada tingkat pelanggan, dengan profil tegangan yang baik, DG lebih lanjut dapat menurunkan arus pada jaringan (Manjunatha Sharma \& Vittal, 2010). 
4) Keunggulan dari program ini adalah cepatnya instalasi karena dengan produk terstandar yang umum di pasaran

5) Rendahnya kerugian akibat transmisi listrik tegangan tinggi (Manjunatha Sharma \& Vittal, 2010). Pada umumnya pembangkit terpusat akan berkumpul pada suatu lokasi yang jauh dari pemukiman, berkumpulnya pembangkit ini tidak hanya terkait masalah lingkungan tetapi juga faktor keuntungan geografis dan ketersediaan jaringan. Indeks reduksi rugi daya akan semakin tinggi dengan tingginya beban pada jaringan listrik.

6) Tercapainya target baik yang dicanangkan berdasar RUEN ataupun berdasarkan RUPTL

\section{PV dan Load Profile (Pola Pembebanan Jaringan)}

Pada gambar 4 adalah data kondisi sistem jaringan operasi P3B pada November 2017. terlihat fluktuasi beban dari 21 GW pada pukul 6 pagi dan mencapai puncak pada jam 6 sore yang mencapai 25 GW, kenaikan beban di siang hari adalah seiring beroperasinya jam kerja ataupun industri, beban sedikit turun pada jam makan siang dan naik kembali setelah jam istirahat selesai. Pada sore hari ketika industri, komersial maupun perkantoran mulai tutup pada sore hari, sektor rumah tangga mulai menggunakan listrik hingga malam hari waktu istirahat. Pembangkit konvensional akan menerima beban sisa, dan yang perlu diperhatikan adalah akan beroperasi dengan kenaikan cukup tinggi pada saat sore hari saat matahari mulai terbenam.

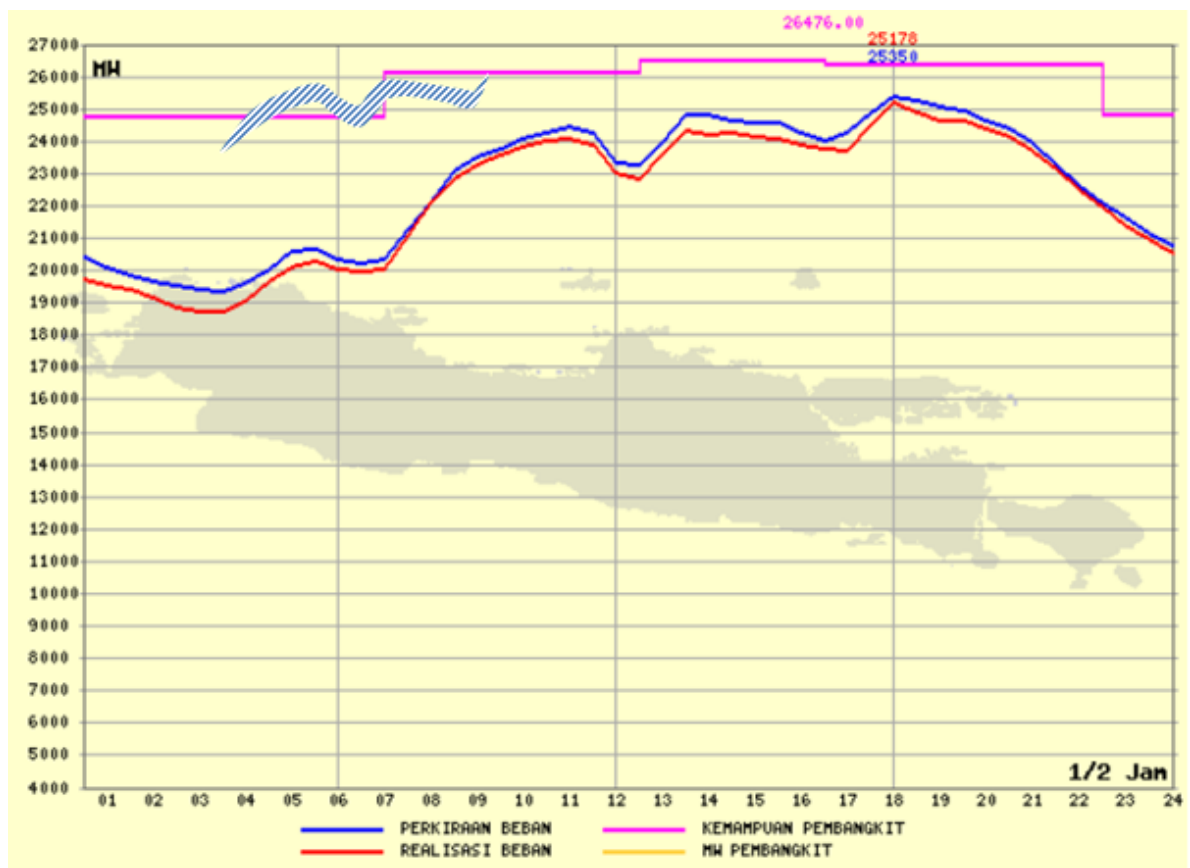

Gambar 4. Kurva Beban Harian yang Terpantau pada Web Bidang Operasi Sistem P3B

Bagaimanapun usaha meminimalisasi efek pembangkit PV atap on-grid ini tetap tidak mungkin menghilangkan efek intermitennya kecuali dengan aplikasi penyimpanan energi. Sehingga pada awal program ini ditujukan untuk mengkompensasi naiknya beban pada hari kerja di siang hari sehingga pada titik ini program PV atap on-grid dirancang tidak menggunakan penyimpanan energi listrik. Dengan pendistribusian yang merata di seluruh wilayah Jawa-Bali diharapkan suplai listrik lebih stabil, jikalau terjadi perubahan cuaca lokal maka dampaknya diprediksi tidak terlalu besar dibandingkan PLTS terpusat. 


\section{Aspek - Aspek Perencanaan pada Program PV Atap On-grid}

Terkait dengan program ini ada beberap aspek yang bisa dijadikan catatan agar program dapat menarik pelanggan PLN untuk berpartisipasi dengan berbagai kemudahan baik dari sisi teknis/teknologi maupun ekonomi, antara lain

1) Komponen produksi dalam negeri

Sesuai amanat RUEN, komponen utama PV di harapkan dapat diproduksi sendiri oleh industri dalam negeri. Pemerintah perlu secara terbuka memberi kesempatan pada kalangan industri untuk memasok komponen PV dengan spesifikasi teknis yang distandarisasi oleh PLN. Hal ini akan membuka rantai produksi baru yang dapat mendorong perekonomian. Karena sifat program adalah bertahap dan akan berlangsung dalam jangka waktu lama, maka rantai produksi diharapkan dapat berkesinambungan, dan ivestor dapat berinvestasi dengan lebih baik.

2) PV terjangkau

Perlunya dukungan agar PV agar bisa menjadi lebih murah, hal yang bisa dilakukan yaitu :

a. Pada awal program perlu pembebasan pajak pada produk PV dan peralatan yang terkait langsung dengannya. Pembebasan pajak ini terasa lebih masuk akal karena di satu sisi jika harga PV mahal maka biaya program juga mahal sehingga mengurangi minat pelanggan PLN yang bersedia menginstalasi PV karena terlalu lama untuk bisa memperoleh manfaat secara langsung, di sisi lain semakin lamanya break event point pemerintah harus menyediakan subsidi yang juga lebih lama. Kaitan dengan subsidi ini bisa dilihat pada poin 3 di bawah.

b. Dukungan riset dan pengembangan. pemerintah memberi dukungan pada lembaga pendidikan atau badan riset baik milik pemerintah atau swasta untuk memfokuskan penelitian pada bidang PV, antara lain pendirian pusat riset yang memberi arahan riset berikut pendanaannya pada prioritas teknologi yang ingin dicapai dan berguna secara langsung pada proses produksi peralatan PV dengan tujuan efisiensi yang lebih baik dan produksi yang lebih murah pada jangka pendeknya dan riset berkelanjutan untuk inovasi lebih jauh pada jangka panjangnya.

c. Akses Teknologi. Produsen yang mengajukan diri terkait dengan program dapat mendapatkan akses teknologi dari pusat riset dan beberapa persyaratan tertentu sehingga pada produk akhirnya pemerintah dapat memberikan standar harga yang tetap menguntungkan kedua belah pihak.

d. Pemberian insentif khusus pada produsen PV dan produsen peralatan yang terkait dengannya yang dikaitkan dengan kandungan lokal produk.

3) Pilot Project

Pada awal program perlu adanya pilot project yang mensimulasi desain dan pola kerja terstandar dari program sebelum diaplikasikan ke seluruh jaringan PLN. Dengan pilot project ini diharapkan akan dapat diperoleh gambaran secara teknis dan ekonomi program yang tepat. Gambaran teknis akan digunakan sebagai blueprint peralatan teknis yang dibutuhkan untuk di berikan kepada produsen dalam negeri atau produsen lain dengan persyaratan yang memenuhi peraturan seperti kandungan lokal sesuai amanat KEN/RUEN. Sedangkan gambaran ekonomi akan memberikan pola pembiayaan yang tepat, dan dapat 
menentukan prioritas penerima program sehingga program dapat berjalan dan memberi hasil maksimal

4) Program pembiayaan terpusat

Pemerintah menyelenggarakan program pembiayaan dan penjaminan secara masal pada semua pelanggan PLN terkoneksi jaringan agar pelanggan bisa memasang PV on-grid. Dengan program pembiayaan dan penjaminan terpusat maka semua pelanggan terkoneksi memiliki kemudahan dan kesempatan yang sama untuk bisa menikmati program. Selain itu pembiayaan bisa jauh lebih murah karena pemerintah diharapkan bisa mengusahakan pembiayaan jangka panjang berbunga rendah, karena jangka waktu program yang panjang hingga 10 tahun.

5) Pelanggan dan subsidi listrik

Semua pelanggan PLN yang terkoneksi jaringan idealnya dapat memanfaatkan PV dengan skema tertentu untuk lebih merangsang pemasangan PV pada tiap rumah baik penerima subsidi maupun bukan. Skema penerima subsidi adalah pengalihan subsidi pada subsidi pemsangan PV, karena pemberian subsidi langsung pada kWh pada konsumen akhir pelanggan jaringan listrik PLN membuat masyarakat tidak menyadari bahwa pemerintah telah memberi banyak subsidi pada tiap $\mathrm{kWh}$, dan subsidi ini akan terus berkepanjangan. Gambaran secara sederhana untuk pelanggan antara lain:

a. Pelanggan terkoneksi jaringan yang tidak menerima subsidi dapat memanfaatkan program, dengan memakai skema PV pay it self atau PV terbayar dengan sendirinya. Pemasangan PV yang mengikuti program pemerintah ini, pelanggan akan tetap membayar listrik sesuai dengan $\mathrm{kWh}$ yang dipakainya baik yang berasal dari jaringan maupun hasil PV, ekspor PV akan dihitung sebagai angsuran pembayaran program PV. Pelanggan akan menikmati pengurangan tagihan listrik setelah program PVnya memenuhi break even point atau lunas.

b. Pelanggan terkoneksi jaringan penerima subsidi akan dialihkan subsidinya dari subsidi tiap kWH ke subsidi pemasangan PV. Dengan pengalihan subsidi pelanggan akan menerima tagihan sesuai konsumsi listrik tanpa subsidi namun menerima pengurangan kWh dari produksi PV yang terpasang di rumah nya masing-masing. Pemerintah pada sementara waktu akan menanggung pembiayaan PV, dan ketika PV telah memenuhi pelunasannya (payback payment), pelanggan akan menerima pengurangan secara permanen tergantung dari usia PV, sementara pemerintah tidak lagi mengeluarkan subsidi karena instalasi PV telah BEP.

c. Pelanggan yang menerima listrik gratis terkoneksi jaringan akan tetap menerima jaringan listrik gratis namun dengan kewajiban pelanggan untuk menyediakan perawatan sederhana PV, sehingga PV dapat berumur lebih panjang. Saat PV telah BEP maka pemerintah tidak lagi memberikan subsidi pada pelanggan PLN

Pada tipikal pembangkit PV jika diambil pembiayaan 10 tahun maka pelanggan akan menikmati manfaat PV pada 20 tahun berikutnya jika diambil rata-rata umur PV sekitar 30 tahun, bahkan beberapa sumber menyatakan PV bisa mencapai umur 40 sampai 50 tahun.

6) Kemudahan instalasi yang terstandarisasi dan perawatan PV

Dengan terstandarisasinya instalasi sebagai hasil riset maupun masukan dari pilot project maka masyarakat akan menerima kemudahan dalam banyak hal, termasuk kemudahan 
pada troubleshooting sederhana maupun diseminasi perawatan PV sederhana dan kemudahan sparepart. Perawatan PV pun sangat sederhana, praktis cukup dengan menjaga permukaan PV tetap bersih dengan cara mencucinya beberapa kali dalam setahun sudah cukup.

7) PLN menyelenggarakan arahan teknis dengan penerbitan aturan dan penunjukan pada kontraktor-kontraktor berlisensi yang bisa melakukan instalasi pada pelanggan dan kemudahan sparepart.

8) Makalah ini sejalan dengan revisi Peraturan Mentri no 50 tahun 2019 (Peraturan Menteri Energi Dan Sumber Daya Mineral no 50 tahun 2017 Tentang Pemanfaatan Sumber Energi Terbarukan Untuk Penyediaan Tenaga Listrik, 2017) dengan PerMen No 4 tahun 2020 terutama pasal 5 Pembelian Tenaga Listrik dari PLTS Fotovoltaik ayat 6 mengenai penghapusan skema BOOT (Built, Owned, Operate, Transfer) (ESDM, 2020), yang artinya pemilik PLTS tidak berkewajiban untuk transfer pembangkit kepada PLN, sehingga dapat menerima manfaat program instalasi PV secara berkelanjutan.

9) Sesuai dengan peraturan ESDM no 49 tahun 2018, bahwa harga jual keluaran PV atap yang dihasilkan akan diberi harga 65\% (ESDM, 2019b) dari ekspor yang tercatat pada KWh meter ekspor impor. Dengan harga tersebut dari sisi pelanggan tentu masih masuk akal karena pelanggan masih terkoneksi dengan jaringan dan masih bisa menerima listrik dari jaringan saat PV tidak menghasilkan listrik. sedangkan dari sisi jaringan, PLN akan menerima penjualan listrik dari PV dengan harga yang sangat murah, bila program produksi hulu hilir PV dapat tercapai, dan biaya instalasi PV lebih murah, maka harga jual per KWh dapat bersaing dengan EBT hydro ataupun PLTU batubara atau gas.

10) Bahkan jika memungkinkan akan adanya program asuransi PV sehingga ketika PV dan peralatan pendukungnya telah terdegradasi atau kapasitas/efisiensinya turun terlalu rendah atau mengalami kerusakan pelanggan akan menerima penggantian sehingga program ini dapat bekesinambungan.

11) Ketika program telah berjalan dan pada saat teknologi baterai sudah mencapai tahap matang dengan siklus yang lebih lama dengan harga lebih murah tentu akan jauh lebih mudah untuk mengupgrade instalasi mikro PV rumah sehingga dapat digunakan terusmenerus 24 jam.

12) Masih memerlukan studi lebih lanjut, bahwa skema on-grid tanpa penyimpanan yang melayani peningkatan kebutuhan listrik pada jam kerja siang hari, pada suatu titik akan mengalami kejenuhan karena sifat intermitennya. Karena pada sisi pembangkit base load yang mayoritas adalah PLTU batubara memiliki keterbatasan start up/shut down yang lambat, terbatas siklusnya dan berbiaya besar sementara ia juga memiliki keterbatasan beban minimum yang tetap harus dihasilkan dengan alasan keamanan operasional. Sehingga ketika program ini telah jenuh pada bagian program lanjutan PLTS atap dengan baterai mungkin bisa dipertimbangkan sebagai program tahap berikutnya.

13) Kelemahan Program

a. Dari sisi perawatan PV meskipun sangat sederhana namun perlu mendapat perhatian agar konsumen yang memanfaatkan program dapat terus mendapat penghematan dalam jangka waktu yang panjang. 
b. Pembangkit terdistribusi ini tidak terkontrol dalam sistem dispatching padahal memiliki sifat intermiten, perlu studi lebih lanjut terutama ketika program telah masif, terkait dengan suplai di saat kebutuhan sangat rendah, seperti akhir minggu, sementara pembangkit base load telah beroperasi pada tingkat minimum operasi aman.

c. Pengelolaan limbah. Dengan semakin masifnya penggunaan mikro PV apalagi dengan jangkauan area yang sangat luas akan berpotensi menghasilkan limbah baik dari PV itu sendiri maupun pada proses pembuatannya. Pada proses pembuatannya akan terkait langsung dengan regulasi, sementara limbah PV yang berada di masyarakat memerlukan edukasi agar tidak membuangnya sembarangan.

\section{Kesimpulan}

Program PV atap on-grid ini memiliki beberapa keunggulan, selain dengan kemudahan tercapainya target EBT dari energi surya yang ditetapkan baik dalam RUEN ataupun RUPTL, juga diperolehnya harga jual perKWh PV program yang jauh lebih rendah dari pada PV terpusat bila dapat diaplikasikan inovasi skema yang baik. Model ini juga diperkirakan lebih baik karena dengan alokasi sebaran yang tetap dapat meminimalisasi penurunan output akibat perubahan cuaca lokal

Pada sisi lain pemerintah dapat memangkas subsidi secara bertahap dan bahkan pada peserta program tidak ada lagi subsidi setelah program instalasi PV selesai. Instalasi PV atap on grid dari beberapa penelitian simulasi maupun eksperimen akan terbayar dengan sendirinya meskipun dalam jangka waktu yang panjang.

Dengan adanya PV atap masyarakat akan terdorong untuk menggunakan energi listrik sebagai basis pada mayoritas aktivitas. Misalnya penggantian peralatan memasak dari kompor gas menjadi kompor listrik/induksi/mikrowave, Peralihan kendaraan atau peralatan berbasis minyak dan gas menjadi basis listrik, seperti mobil listrik, kompressor listrik dan sebagainya. Perubahan pola ini bisa membantu pemerintah mengurangi subsidi pada BBM maupun BBG yang digunakan masyarakat.

\section{Daftar Pustaka}

Allik, A., \& Annuk, A. (2018). An Alternative Approach to the Feasibility of Photovoltaic Power Stations in Light of Falling PV Panel Prices. 7th International IEEE Conference on Renewable Energy Research and Applications, ICRERA 2018, October 2018, 270-274. https://doi.org/10.1109/ICRERA.2018.8566762

Bhadoria, V. S., Pal, N. S., \& Shrivastava, V. (2013). A Review on Distributed Generation Definitions and DG Impacts on Distribution System. International Conference on Advanced Computing and Communication Technologies, November, 1-7. https://doi.org/10.13140/RG.2.1.4439.4328

BPPT. (2019). Indonesia Energy Outlook 2019: The Impact of Increased Utilization of New and Renewable Energy on the National Economy.

BPS. (2018). BADAN PUSAT STATISTIK BPS-Statistics Indonesia. 85.

DEN. (2019). Indonesia Energy Outlook. In ESDM. https://www.esdm.go.id/assets/media/content/content-outlook-energi-indonesia-2019-bahasaindonesia.pdf

DEN. (2020). Bauran Energi Nasional. 
Peraturan Menteri Energi Dan Sumber Daya Mineral no 50 tahun 2017 Tentang Pemanfaatan Sumber Energi Terbarukan Untuk Penyediaan Tenaga Listrik, (2017) (testimony of ESDM). http://library1.nida.ac.th/termpaper6/sd/2554/19755.pdf

ESDM. (2018). Kepmen 1567 Pengesahan RUPTL tahun 2018 s/d 2027.687. http://library1.nida.ac.th/termpaper6/sd/2554/19755.pdf

ESDM. (2019a). Statistik Ketenagalistrikan Tahun 2019 (Vol. 53, Nomor 9).

ESDM. (2020). Peraturan Menteri Energi dan Sumber Daya Mineral no 4 Tahun 2020.

ESDM, K. (2019b). Nomor 49 Tahun 2018 Penggunaan Sistem Pembangkit Listrik Tenaga Surya Atap oleh Konsumen PT Perusahaan Listrik Negara (PLN).

Fidalgo, J. N., Fontes, D. B. M. M., \& Silva, S. (2009). A Decision Support System to Analyze the Influence of Distributed Generation in Energy Distribution Networks. September 2001, 59-77. https://doi.org/10.1007/978-3-540-88965-6_4

Karpouzoglou, T., Vlaswinkel, B., \& Van Der Molen, J. (2020). Effects of large-scale floating (solar photovoltaic) platforms on hydrodynamics and primary production in a coastal sea from a water column model. In Ocean Science (Vol. 16, Nomor 1, hal. 195-208). https://doi.org/10.5194/os-16195-2020

Liebensteiner, M., \& Wrienz, M. (2020). Do Intermittent Renewables Threaten the Electricity Supply Security? Energy Economics, 87. https://doi.org/10.1016/j.eneco.2019.104499

Manjunatha Sharma, K., \& Vittal, K. P. (2010). A heuristic approach to Distributed Generation source allocation for electrical power distribution systems. Iranian Journal of Electrical and Electronic Engineering, 6(4), 224-231.

Perpres. (2017). Peraturan Presiden Nomor 22 Tahun 2017 tentang Rencana Umum Energi Nasional. 4(1), 139. https://doi.org/10.38011/jhli.v4i1.53

PT.PLN (Persero). (2019). Statisik PLN 2019.

Solargis. (2017). Global Map of Photovoltaic Power Potential. The World Bank.

Windarta, J., Saptadi, S., Denis, Satrio, D. A., \& Silaen, J. S. (2020). Economic Feasibility Analysis of Rooftop Solar Power Plant Design with Household-Scale On-grid System in Semarang City. E3S Web of Conferences, 202(4). https://doi.org/10.1051/e3sconf/202020209002 